\title{
Optically Illuminated 4H-SiC Terahertz IMPATT Device
}

\author{
M. Mukherjee and N. Mazumder \\ Department of Applied Physics, International Institute of Information \\ Technology, Visva Bharati University, X-1, 8/3, Block EP, Sector V \\ Salt Lake Electronics Complex, Kolkata 700091, INDIA
}

The dynamic properties of a $4 \mathrm{H}-\mathrm{SiC}$ DDR $\left(p^{+} p \quad n n^{+}\right.$type) IMPATT diode operating at $0.5 \mathrm{THz}$ region are studied through $D C$ and smallsignal analysis. The study indicates that 4H-SiC IMPATT is capable of generating high $R F$ power $\left(P_{R F}\right)(2.70 \mathrm{~W})$ at 0.515 terahertz with high efficiency (12\%). However, the parasitic series resistance is found to produce a $7 \%$ reduction in the negative conductance and the $P_{R F}$ of the diode. The effect of photo-illumination on the device is also investigated by studying the role of enhanced saturation current on the THz frequency performance of this IMPATT device. A modified double iterative simulation technique developed by the authors is used for this purpose. It is found that (i) the negative conductance and (ii) the negative resistance of the device decrease, while, the frequency of operation and the device quality factor shift upward with increasing saturation current. The upward shift in operating frequency is found to be more $(\sim 65 \mathrm{GHz})$ when the device performance is controlled by the hole saturation current rather than by the electron dominated saturation current. These results thus indicate that $4 \mathrm{H}$-SiC DDR IMPATT diode is highly photo-sensitive even at $\mathrm{THz}$ range of frequencies.

\section{Introduction}

The terahertz $(\mathrm{THz})$ regime $(0.1-10 \mathrm{THz})$ is rich with emerging possibilities in remote sensing, imaging and communications, with unique applications for detecting hidden biological weapons and explosives. Since the last decade, scientists working in this area are showing significant interest to develop solid state sources that may generate THz power. Among all twoterminal semiconductor devices (Gunn, IMPATT, TRAPATT, BARITT etc.), IMPATT $^{1}$ devices have already emerged as the most efficient solid state sources that can deliver highest RF power even at $300 \mathrm{GHz}$ [1]. For realizing higher RF power $\left(\mathrm{P}_{\mathrm{RF}}\right)$ from an IMPATT device, one should choose a 
semiconductor material that has higher values of critical electric field $\left(\mathrm{E}_{\mathrm{c}}\right)$ and saturated carrier drift velocity $\left(\mathrm{v}_{\mathrm{s}}\right)$, since the $\mathrm{P}_{\mathrm{RF}}$ of an IMPATT device is proportional to $\mathrm{E}_{\mathrm{c}}^{2} \cdot \mathrm{v}_{\mathrm{s}}^{2}$. Although the conventional IMPATT diodes fabricated on GaAs (Gallium Arsenide) and Si (Silicon) are found to be reliable, these are limited by power and operating frequencies due to the fundamental limitations of the material parameters. On the other hand, wide band gap semiconductor like 4H-SiC (Silicon Carbide) has excellent material properties that can be explored to develop high power IMPATT devices. The authors have, therefore, designed IMPATT diodes based on $4 \mathrm{H}-\mathrm{SiC}$, since this material offers (i) 10 times higher $\mathrm{E}_{\mathrm{c}}$, (ii) 2 times higher $\mathrm{v}_{\mathrm{s}}$ and (iii) 3 times the thermal conductivity, in comparison to those of $\mathrm{Si}$ and GaAs as given in (Table 1) .

Table (1): Material parameters of $4 \mathrm{H}-\mathrm{SiC}, \mathrm{GaAs}$ and $\mathrm{Si}$

\begin{tabular}{|c|c|c|c|}
\hline & $4 \mathrm{H}-\mathrm{SiC}$ & $\mathrm{GaAs}$ & $\mathrm{Si}$ \\
\hline $\begin{array}{c}\text { Band Gap Energy }\left(\mathrm{E}_{\mathrm{g}}\right) \\
(\mathrm{eV})\end{array}$ & 3.26 & 1.43 & 1.12 \\
\hline $\begin{array}{c}\text { Thermal Conductivity } \\
(\mathrm{W} / \mathrm{cm}-\mathrm{K})\end{array}$ & 4 & 0.50 & 1.50 \\
\hline $\begin{array}{c}\text { Electron saturation velocity } \\
\left(\mathrm{v}_{\mathrm{s}}\right) \\
(\mathrm{cm} / \mathrm{sec})\end{array}$ & $2.2 \times 10^{7} *$ & $1 \times 10^{7}$ & $1 \times 10^{7}$ \\
\hline $\begin{array}{c}\text { Breakdown field (E } \\
(\mathrm{V} / \mathrm{cm})\end{array}$ & $3.5 \times 10^{6}$ & $4 \times 10^{5}$ & $3 \times 10^{5}$ \\
\hline
\end{tabular}

* measured perpendicular to c-axis

4H-SiC has an energy band gap approaching $3.3 \mathrm{eV}$ at room temperature, enabling the devices based on this material to support peak internal electric fields $\left(\mathrm{E}_{\mathrm{c}}\right)$ about ten times higher than $\mathrm{Si}$ and GaAs. Higher $\mathrm{E}_{\mathrm{c}}$ results in higher breakdown voltage, an essential criterion of a device for generating high power. Higher $\mathrm{E}_{\mathrm{c}}$ also permits incorporation of higher doping level $\left(\mathrm{N}_{\mathrm{D}}\right)$ in the depletion layer of the device, which in turn, reduces the width of the active region. That means, device layers can be made very thin. The transit time of carriers becomes very small in a thin layered semiconductor if the carrier drift velocity is high. The material parameters of $4 \mathrm{H}-\mathrm{SiC}$ are favorable for realizing smaller transit time. This feature in a 4H-SiC IMPATT diode makes it a potential candidate for operation in the $\mathrm{THz}$ range of frequencies, a region unapproachable by conventional IMPATTs due to the high frequency limitations imposed by the material parameters. Further, the high value of thermal conductivity for $\mathrm{SiC}$ provides better thermal stability for high power operation of such devices.

Only a few experimental and theoretical studies on 4H-SiC IMPATT diodes have been reported so far [2-4]. Simulation results, reported by Yuan et 
al, predicted a maximum power output of $150 \mathrm{~W}$ at $35 \mathrm{GHz}$ with $23 \%$ efficiency at a dc bias current density of $9.5 \mathrm{kA} / \mathrm{cm}^{2}$ [2]. Vassilevski et.al fabricated a $4 \mathrm{H}-\mathrm{SiC}$ IMPATT diode with $\mathrm{p}^{+} \mathrm{n}^{+}$doping profile and obtained a pulsed power of about $300 \mathrm{~mW}$ at X-band frequencies [4].

However, there is still an emergent need for developing solid state high power IMPATT oscillators for operation in the $\mathrm{THz}$ region. To meet this gradual demand, the authors have simulated and studied the dc and small signal behavior of a DDR ${ }^{2}\left(\mathrm{p}^{+} \mathrm{p} \mathrm{n} \mathrm{n}^{+}\right.$type) 4H-SiC IMPATT diode suitable for operation at $\mathrm{THz}$ frequency range. The schematic diode structure and doping profile of the designed DDR diode is shown in Fig. (1).

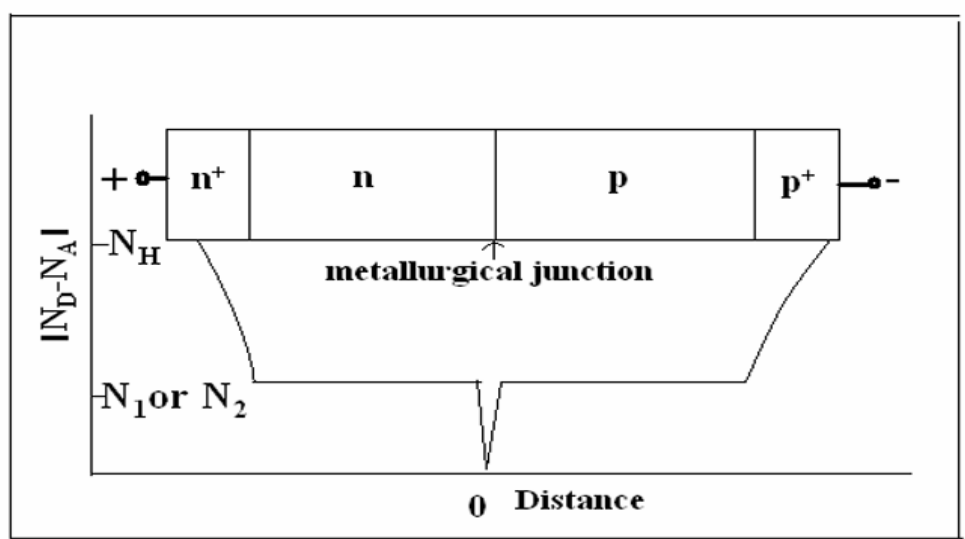

Fig.(1): Schematic diode structure and doping profile of a flat profile DDR IMPATT diode $\left(\mathrm{N}_{1}\right.$ or $\mathrm{N}_{2}$ is flat epilayer doping concentration and $\mathrm{N}_{\mathrm{H}}$ is substrate doping concentration).

Optical control of the dynamic properties of IMPATT devices at $\mathrm{THz}$ frequency range can have tremendous application in advanced radars and space-communication systems. IMPATT oscillators used as THz sources in spacecrafts may be subjected to interstellar radiation that can produce appreciable changes in the performance of the oscillators. Basic process involved is that, when a photon (due to optical /other radiation) of energy hv greater than the band gap of the semiconductor is absorbed at the edges of the reversed biased p-n junction of an IMPATT diode, creation of additional electron-hole pairs takes place within the active region of the diode. These photo-generated carriers give rise to photocurrent and thereby enhance the existing thermal leakage current in the IMPATT diode. The enhanced leakage current alters the avalanche phase delay in the diode, which subsequently modifies the phase and magnitude of terminal current in the device oscillator circuit. The previous experimental [5-6] as well as theoretical [7-9] studies on 
optically illuminated IMPATT diodes indicate that photo-generated carriers reduce the efficiency and power output of the devices, but increase the tuning range of the devices in the mm-wave frequency band.

This paper will present the results of simulated design of $4 \mathrm{H}-\mathrm{SiC}$ based DDR IMPATT diode having flat doping profile, optimized for $\mathrm{THz}$ frequency operation. The authors have also assessed the performance of the THz IMPATT oscillator under optical illumination and the results are reported in the present article.

\section{Computer Simulation Method:}

The IMPATT diode is basically a p-n junction diode that operates when it is reverse-biased to avalanche breakdown condition. The active layer of a reverse biased p-n junction is shown in Fig. (2). A one-dimensional model of the p-n junction has been considered in the present analysis. The following assumptions have been made in the simulation of $\mathrm{dc}$ and small signal behavior of $4 \mathrm{H}-\mathrm{SiC}$ DDR IMPATT diode: (i) the electron and hole velocities have been taken to be saturated and independent of the electric field throughout the space-charge layer, (ii) the effect of carrier space-charge has been considered, and (iii) the effect of carrier diffusion has been neglected.

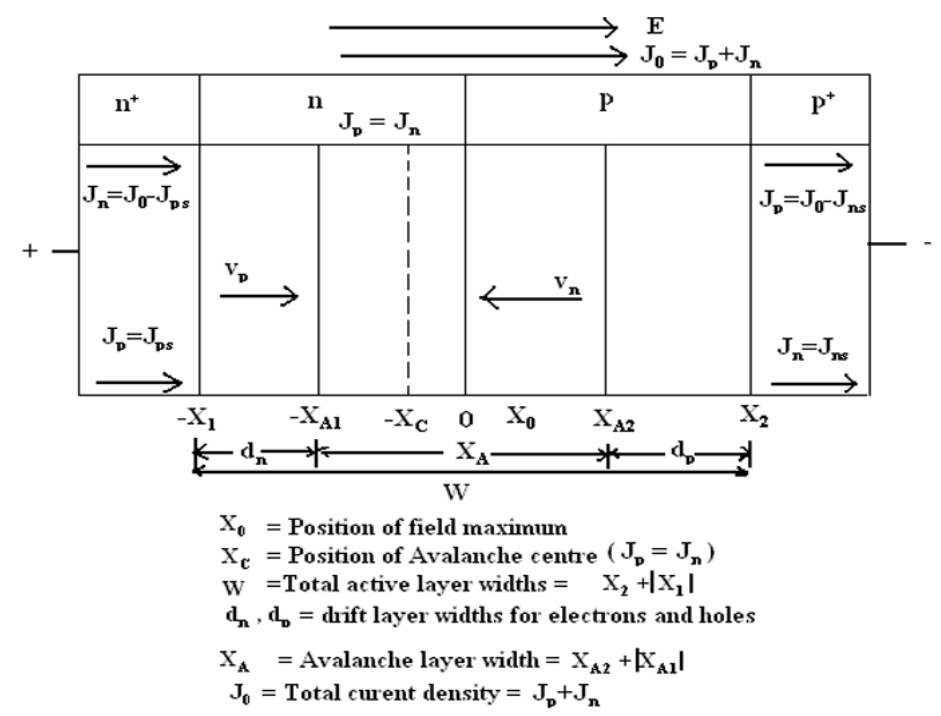

Fig.(2): 'The active layer of a reverse biased $p-n$ junction.

\subsection{Analysis:}

The dc method, described in details elsewhere [10], considers a generalized $\left(\mathrm{n}^{++} \mathrm{n} \mathrm{p} \mathrm{p} \mathrm{p}^{++}\right)$structure. Here, $\mathrm{n}^{++}$and $\mathrm{p}^{++}$are highly doped substrates and $\mathrm{n}$ and $\mathrm{p}$ are epilayers. Summarily, in the dc method, the computation starts from the field maximum near the metallurgical junction. 
The distribution of dc electric field and carrier currents in the depletion layer are obtained by a double-iterative simulation method, which involves iteration over the magnitude of field maximum $\left(\mathrm{E}_{\mathrm{m}}\right)$, and its location in the depletion layer. The method is used for a simultaneous solution of Poisson and carrier continuity equations at each point in the depletion layer. The field boundary conditions are given by,

$$
\mathrm{E}(-\mathrm{x} 1)=0 \text { and } \quad \mathrm{E}(+\mathrm{x} 2)=0
$$

Here $-\mathrm{x}_{1}$ and $\mathrm{x}_{2}$ represent the edges of the depletion layer in $\mathrm{n}$ and $\mathrm{p}$ regions, respectively.

The boundary conditions for normalized current density $\mathrm{P}(\mathrm{x})$, are given by,

$$
\mathrm{P}\left(-\mathrm{x}_{1}\right)=\left(2 / \mathrm{M}_{\mathrm{p}}-1\right) \text { and } \mathrm{P}\left(\mathrm{x}_{2}\right)=\left(1-2 / \mathrm{M}_{\mathrm{n}}\right)
$$

Where: $M_{n}=J / J_{n s}, M_{p}=J / J_{p s}$ where $J_{n s}$ and $J_{p s}$ are electron and hole leakage current densities, respectively.

$M_{p}$ and $M_{n}$ are hole and electron current multiplication factors, respectively.

$\mathrm{P}=\left(\mathrm{J}_{\mathrm{p}}-\mathrm{J}_{\mathrm{n}}\right) / \mathrm{J}$, where $\mathrm{J}_{\mathrm{p}}=$ hole current density, $\mathrm{J}_{\mathrm{n}}=$ electron current density and $\mathbf{J}=$ total current density.

Thus, the dc field and carrier current profiles are obtained by solving Poisson and carrier continuity equations, when boundary conditions (1) and (2) are satisfied. The realistic field dependence of electron and hole ionization rates, carrier mobility, and the saturated drift velocities of electron $\left(\mathrm{v}_{\mathrm{s}, \mathrm{n}}\right)$ and hole $\left(\mathrm{v}_{\mathrm{s}, \mathrm{p}}\right)$ are used in the computation for the profiles of electric field and carrier currents.

The d.c. to mm-wave conversion efficiency $(\eta)$ [11] is calculated from the approximate formula,

$$
\eta(\%)=(\mathrm{VD} \times 100) /(\pi \times \mathrm{VB})
$$

where, $V_{D}=$ voltage drop across the drift region. Also, $V_{D}=V_{B}-V_{A}$, where, $V_{A}$ $=$ voltage drop across the avalanche region, and, $\mathrm{V}_{\mathrm{B}}=$ breakdown voltage.

Avalanche breakdown occurs in the junction when the electric field is large enough such that the charge multiplication factors $\left(M_{n}, M_{p}\right)$ become infinite. The breakdown voltage is calculated by integrating the spatial field profile over the total depletion layer width, i.e.,

$$
\mathrm{x}_{2}
$$




$$
\mathrm{V}_{\mathrm{B}}=\int_{-\mathrm{x}_{1}} \mathrm{E}(\mathrm{x}) \mathrm{dx}
$$

where, $-\mathrm{x}_{1}=\mathrm{n}$-side depletion layer width

and, $\quad+\mathrm{x}_{2}=\mathrm{p}$-side depletion layer width

The results of the dc analysis are then used in the small signal analysis, described briefly in the next sub-section.

\subsection{Small Signal Analysis:}

The small signal analysis of the IMPATT diode provides insight into the high frequency performance of the diode. The range of frequencies exhibiting negative conductance of the diode can easily be computed by Gummel-Blue method [12]. From the dc field and current profiles, the spatially dependent ionization rates that appear in the Gummel-Blue equations are evaluated, and fed as input data for the small signal analysis. The edges of the depletion layer of the diode, which are fixed by the dc analysis, are taken as the starting and end points for the small signal analysis. On splitting the diode impedance $\mathrm{Z}(\mathrm{x}, \omega)$ obtained from Gummel-Blue method, into its real part $\mathrm{R}$ $(\mathrm{x}, \omega)$ and imaginary part $\mathrm{X}(\mathrm{x}, \omega)$, two differential equations are framed [10]. A double-iterative simulation scheme incorporating modified Runge-Kutta method is used to solve these two equations simultaneously. The small signal integrated parameters like negative conductance (-G), susceptance (B), impedance $(\mathrm{Z})$, frequency band width, and the quality factor $(\mathrm{Q})$ of the diode are obtained satisfying the boundary conditions derived elsewhere [7].

\subsubsection{Small Signal Device Parameters}

The simulation method provides the high-frequency negative resistance and negative reactance profiles in the space-charge layer of the device. The diode negative resistance $\left(-Z_{R}\right)$ and reactance $\left(-Z_{x}\right)$ are computed through numerical integration of the $-\mathrm{R}(\mathrm{x})$ and $-\mathrm{X}(\mathrm{x})$ profiles over the active spacecharge layer.

Thus,

$$
-Z_{R}=\int_{-X_{1}}^{X_{2}}-R d x, \quad \text { and } \quad-Z_{X}=\int_{-X_{1}}^{X_{2}}-X d x
$$

The diode impedance $\mathrm{Z}$ is given by,

$$
Z(\omega)=\int_{-X_{1}}^{x_{2}} Z(x, \omega) d x=-Z_{R}+j Z_{X}
$$

The diode admittance is expressed as, 
or,

$$
Y=1 / Z=-G+j B=1 /\left(-Z_{R}+j Z_{X}\right)
$$

$$
-\mathrm{G}=-\mathrm{Z}_{\mathrm{R}} /\left(\left(\mathrm{Z}_{\mathrm{R}}\right)^{2}+\left(\mathrm{Z}_{\mathrm{X}}\right)^{2}\right) \text { and } \mathrm{B}=\mathrm{Z}_{\mathrm{X}} /\left(\left(\mathrm{Z}_{\mathrm{R}}\right)^{2}+\left(\mathrm{Z}_{\mathrm{X}}\right)^{2}\right)
$$

It may be noted that both $-\mathrm{G}$ and $\mathrm{B}$ are normalized to the area of the diode.

The avalanche frequency $\left(f_{a}\right)$ is the frequency at which the imaginary part, susceptance (B) of the admittance changes its nature from inductive to capacitive. Again, it is the minimum frequency at which the real part, conductance $(\mathrm{G})$ of the admittance becomes negative. At the avalanche frequency oscillation starts to build up in the circuit.

The small signal quality factor $(\mathrm{Q})$ is defined as the ratio of the imaginary part of the admittance to the real part of the admittance (at the peak frequency), i.e.,

$$
-\mathrm{Q}_{\mathrm{p}}=\left(\mathrm{B}_{\mathrm{p}} /-\mathrm{G}_{\mathrm{p}}\right)
$$

At a given bias current density, the peak frequency $\left(f_{p}\right)$ is the frequency at which the negative conductance of the diode is a maximum, and the quality factor is a minimum.

At resonance, the maximum RF power output $\left(\mathrm{P}_{\mathrm{RF}}\right)$ from the device is obtained from the expression [13]:

$$
\mathrm{P}_{\mathrm{RF}}=\left(\mathrm{V}_{\mathrm{RF}}^{2} \cdot \mathrm{G}_{\mathrm{P}} \cdot \mathrm{A}\right) / 2,
$$

where $\mathrm{V}_{\mathrm{RF}}$ (amplitude of the $\mathrm{RF}$ swing) is taken as $\mathrm{V}_{\mathrm{B}} / 5$, assuming a small signal (20\%) modulation of the breakdown voltage $\mathrm{V}_{\mathrm{B}}$ and $\mathrm{A}$ is the area of the diode. The diode negative conductance at the optimum frequency $\left(-G_{p}\right)$ is normalized to the area of the diode. The role of parasitic positive series resistance is also considered for calculating realistic values of $\mathrm{P}_{\mathrm{RF}}$.

\subsection{Simulation Technique for Studying the Illumination Effect}

The leakage current $\left(\mathrm{J}_{\mathrm{s}}\right)$, entering the depletion region of the reversed biased p-n junction of an IMPATT diode, is normally due to thermally generated electrons and holes $\left[\mathrm{J}_{\mathrm{s}}=\mathrm{J}_{\mathrm{ns}(\mathrm{th})}+\mathrm{J}_{\mathrm{ps}(\mathrm{th})}\right]$ and it is so small that current multiplication factor $\mathrm{M}_{\mathrm{n}, \mathrm{p}}=\mathrm{J}_{\mathrm{o}} /\left[\mathrm{J}_{\mathrm{ns}(\text { th) }}\right.$ or $\left.\mathrm{J}_{\mathrm{ps}(\mathrm{h})}\right], \quad\left[\mathrm{J}_{\mathrm{o}}=\right.$ bias current density $]$ can be considered to be infinitely large. Thus, the enhancement of the leakage current under optical illumination of the devices is manifested as the lowering of $\mathrm{M}_{\mathrm{n}, \mathrm{p}}$. The composition of the leakage current (electron versus hole photocurrent) plays a vital role in controlling the microwave properties of the optically illuminated IMPATTs. In a DDR IMPATT structure $\left(\mathrm{p}^{+} \mathrm{p} \mathrm{n} \mathrm{n}^{+}\right.$type), the composition of photocurrent may be altered by shining a laser beam selectively on the $\mathrm{p}^{+}$or $\mathrm{n}^{+}$side of the device through fabricated optical windows 
of appropriate diameter, keeping the diode mounted in a microwave cavity. Thus, the electron saturation current and also the hole saturation current might be enhanced separately, which would produce changes in the $\mathrm{THz}$ performance of the IMPATT.

Under optical illumination, the expression for electron current multiplication factor changes to

$\mathrm{M}_{\mathrm{n}}=\mathrm{J}_{\mathrm{o}} /\left[\mathrm{J}_{\mathrm{ns}(\mathrm{th})}+\mathrm{J}_{\mathrm{ns}(\mathrm{opt} t}\right], \quad\left[\mathrm{J}_{\mathrm{ns}(\mathrm{opt})}=\right.$ saturation current due to photoelectrons $]$.

Thus, the photoelectrons reduce the value of $M_{n}$, while the value of $M_{p}$ remains unchanged.

Again, under optical illumination the expression for hole current multiplication factor changes to

$\mathrm{M}_{\mathrm{p}}=\mathrm{J}_{\mathrm{o}} /\left[\mathrm{J}_{\mathrm{ps}(\mathrm{th})}+\mathrm{J}_{\mathrm{ps}(\mathrm{opt})}\right], \quad\left[\mathrm{J}_{\mathrm{ps}(\mathrm{opt})}=\right.$ saturation current due to photo generated holes].

So, the photo generated holes reduce the value of $M_{p}$, while the value of $M_{n}$ remains unchanged.

In order to assess the role of leakage current in controlling the dynamic properties of IMPATT oscillator at $\mathrm{THz}$ frequencies, simulation studies are carried out by the authors on the effect of $M_{n}$ (keeping $M_{p}$ very high $\sim 10^{6}$ ) and $M_{p}$ (keeping $M_{n}$ very high $\sim 10^{6}$ ) on (i) the small signal admittance characteristics, (ii) the negative resistivity profiles, and (iii) the device quality factor (Q) of flat profile $4 \mathrm{H}-\mathrm{SiC}$ DDR IMPATT. The details of mathematical calculations based on modified boundary conditions due to enhancement of leakage current are described elsewhere [7].

\section{Design Parameters:}

4H-SiC DDR IMPATT diode with flat doping profile has been designed and studied following the dc and small signal methods described above. The experimental values of material parameters, viz., realistic field dependence of carrier ionization rates [14], saturated drift velocities of charge carriers [15-16], and carrier mobility [17] in $4 \mathrm{H}-\mathrm{SiC}$ have been incorporated in the analysis. The junction temperature has been assumed to be $300 \mathrm{~K}$. The diode has been considered to be a circular chip of $8 \mu \mathrm{m}$ diameter. The device dimensions, doping and current densities of the designed diode are listed in Table 2. The device structural parameters and the current density have been optimized for $\mathrm{THz}$ operation through several computer runs. 
Table (2): Design parameters of $4 \mathrm{H}-\mathrm{SiC}$ DDR IMPATT Diode at $\mathrm{THz}$ frequency region

\begin{tabular}{|c|c|c|c|}
\hline $\begin{array}{c}\text { Diode } \\
\text { type }\end{array}$ & $\begin{array}{c}\text { Flat epilayer } \\
\text { Doping conc. } \\
(\mathrm{n} \text { and p regions }) \\
\left(10^{23} \mathrm{~m}^{-3}\right)\end{array}$ & $\begin{array}{c}\text { Width of the } \\
\text { flat epilayer } \\
(\mathrm{n} \text { and } \mathrm{p} \text { regions }) \\
(\mu \mathrm{m})\end{array}$ & $\begin{array}{c}\text { Current density } \\
\left(10^{9} \mathrm{~A} \mathrm{~m}^{-2}\right)\end{array}$ \\
\hline $\begin{array}{c}\text { flat doping } \\
\text { profile }\end{array}$ & 9.5 & 0.16 & 6.0 \\
\hline
\end{tabular}

\section{Results and Discussions}

The optimized design parameters of the unilluminated 4H-SiC DDR IMPATT diode for which $\mathrm{M}_{\mathrm{n}}$ and $\mathrm{M}_{\mathrm{p}}$ are both large $\left(=10^{6}\right)$ are summarized in Table 2. The dc and high frequency properties of this designed $\mathrm{THz}$ diode are reported in Table (3). It is observed from Table 3 that the designed diode is capable of generating $2.7 \mathrm{~W}$ RF power with an efficiency of $12 \%$ at $0.515 \mathrm{THz}$ frequency.

Table (3): MM-wave properties of 4H-SiC DDR IMPATT Diode at $\mathrm{THz}$ region.

\begin{tabular}{|c|c|}
\hline Diode parameters & $\begin{array}{c}\text { 4H-SiC } \\
\text { DDR IMPATT }\end{array}$ \\
\hline $\mathrm{E}_{\mathrm{m}}\left(10^{8} \mathrm{~V} \mathrm{~m}^{-1}\right)$ & 4.3 \\
\hline $\mathrm{V}_{\mathrm{B}}(\mathrm{V})$ & 96.0 \\
\hline $\mathrm{V}_{\mathrm{D}} / \mathrm{V}_{\mathrm{B}}(\%)$ & 37.7 \\
\hline$\eta(\%)$ & 12.0 \\
\hline $\mathrm{f}_{\mathrm{a}}(\mathrm{THz})$ & 0.425 \\
\hline $\mathrm{f}_{\mathrm{p}}(\mathrm{THz})$ & 0.515 \\
\hline$-\mathrm{G}_{\mathrm{p}}\left(10^{6} \mathrm{~S} \mathrm{~m}^{-2}\right)$ & 290.0 \\
\hline$-\mathrm{Q}_{\mathrm{p}}$ & 1.95 \\
\hline $\mathrm{P}_{\mathrm{RF}}(\mathrm{W})$ & 2.7 \\
\hline
\end{tabular}

The value of parasitic series resistance $\left(\mathrm{R}_{\mathrm{S}}\right)$ for $\mathrm{SiC} \mathrm{THz}$ IMPATT is calculated following a method described elsewhere [18] and its effect on $-G_{P}$ and $\mathrm{P}_{\mathrm{RF}}$ are shown in Fig. (3 and 4), respectively. It is interesting to note that due to the presence of $R_{S}(\sim 4.2 \Omega)$, the values of $-G_{P}$ as well as $P_{R F}$ of the unilluminated diodes reduces approximately by $7.0 \%$. 


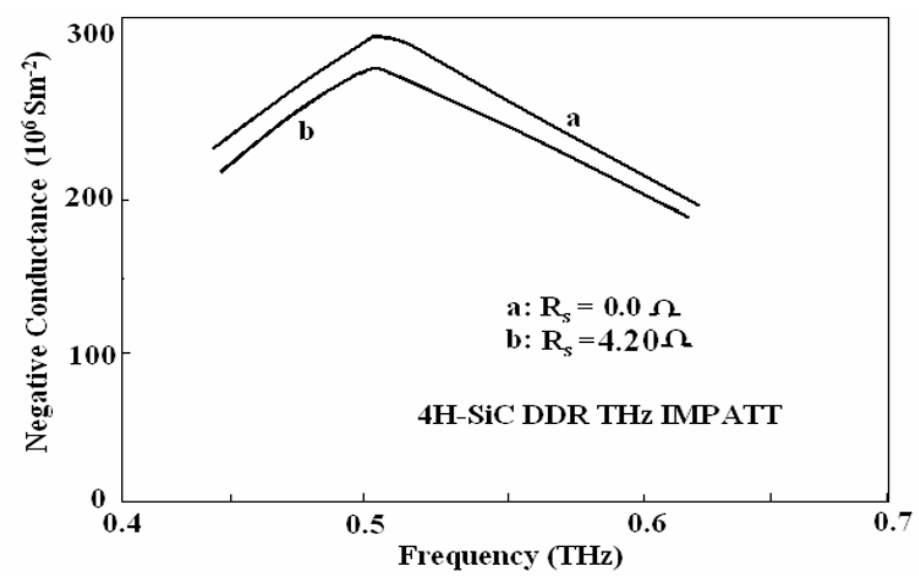

Fig.(3): Plots of negative conductance versus frequency (with and without $R_{S}$ ) for the unilluminated 4H-SiC DDR IMPATT diode operating at THz frequency region.

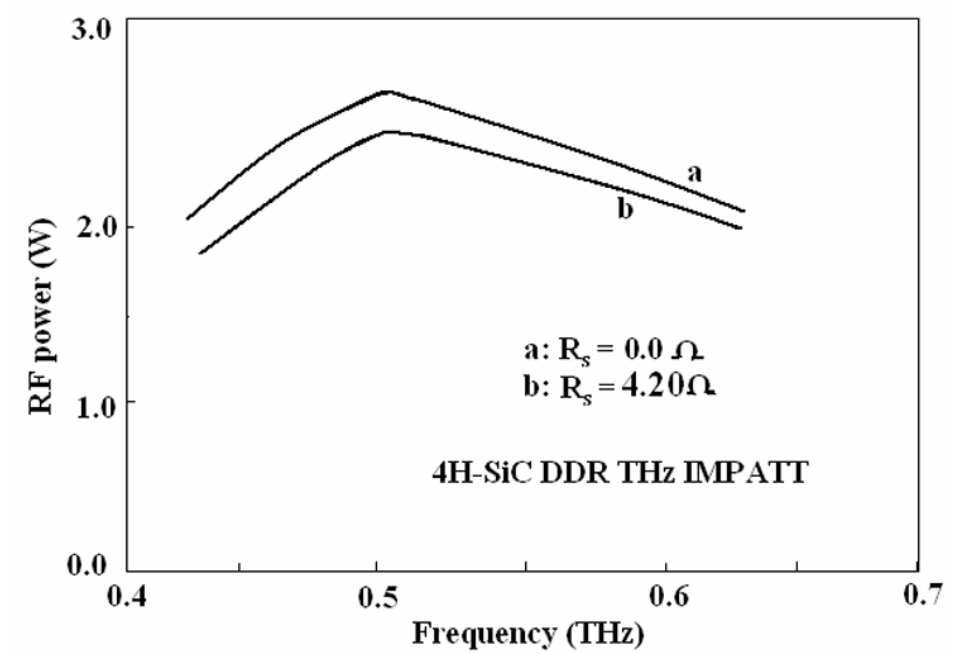

Fig.(4): Plots of RF-power versus frequency (with and without $R_{S}$ ) for the unilluminated 4H-SiC DDR IMPATT diode operating at $\mathrm{THz}$ frequency region.

Table (4) shows the effect of electron and hole dominated photocurrent on the high frequency properties of $4 \mathrm{H}-\mathrm{SiC}$ DDR THz IMPATT. In Figs. (5 and 6), plots of $-\mathrm{G}$ versus $\mathrm{B}$ for $4 \mathrm{H}-\mathrm{SiC}$ DDR IMPATT for different values of $\mathrm{M}_{\mathrm{n}}$ and $M_{p}$ are shown. The graphs show that the values of $\left|-G_{P}\right|$ of the diode decreases with the lowering of $M_{n}$ and $M_{p}$. At the same time, the frequency range over which the device exhibits negative conductance, shifts towards higher frequencies with the lowering of $M_{n}$ and $M_{p}$. The output data for illuminated flat profile DDR IMPATT diode (Table (4)) indicate that the value 
of negative conductance at peak frequency $\left|-\mathrm{G}_{\mathrm{P}}\right|$ decreases by $6 \%$ when $\mathrm{M}_{\mathrm{n}}$ reduces from $10^{6}$ to 10 , while $\left|-\mathrm{G}_{\mathrm{P}}\right|$ decreases by $45 \%$ for the same decrease of $\mathrm{M}_{\mathrm{p}}$ from $10^{6}$ to 10 at a particular current density $\left(\mathrm{J}_{0}=6 \times 10^{9} \mathrm{~A} \mathrm{~m}^{-2}\right)$.

Table (4): Variation of small signal parameters of 4H-SiC THz DDR IMPATT Diode under optical illumination.

\begin{tabular}{|c|c|c|c|c|c|c|}
\hline $\mathrm{M}_{\mathrm{n}}$ & $\mathrm{M}_{\mathrm{p}}$ & $\begin{array}{c}\mathrm{f}_{\mathrm{p}} \\
(\mathrm{THz})\end{array}$ & $\begin{array}{c}-\mathrm{G}_{\mathrm{p}} \\
\left(10^{6} \mathrm{Sm}^{-2}\right)\end{array}$ & $\begin{array}{c}-\mathrm{Z}_{\mathrm{Rp}} \\
\left(10^{-10} \Omega \mathrm{m}^{2}\right)\end{array}$ & $\begin{array}{c}\text { RF Power } \\
(\mathrm{W})\end{array}$ & $-\mathrm{Q}_{\mathrm{p}}$ \\
\hline $1 \times 10^{6}$ & $1 \times 10^{6}$ & 0.515 & 290.0 & 5.45 & 2.70 & 1.95 \\
\hline 100 &, & 0.517 & 287.7 & 5.40 & 2.65 & 2.10 \\
\hline 50 &, & 0.522 & 282.8 & 5.33 & 2.60 & 2.13 \\
\hline 10 & $\#$ & 0.540 & 272.7 & 4.63 & 2.51 & 2.3 \\
\hline $1 \times 10^{6}$ & 100 & & 271.0 & 5.20 & 2.49 & 2.21 \\
& & 0.520 & & & & \\
\hline$\%$ & 50 & 0.530 & 258.6 & 4.63 & 2.38 & 2.40 \\
\hline, & 10 & 0.580 & 160.0 & 2.10 & 1.47 & 4.1 \\
\hline
\end{tabular}

It is further evident from Figs. (5 and 6) that for $\mathrm{THz}$ operation of the 4H-SiC IMPATT, a lowering of $\mathrm{M}_{\mathrm{p}}$ causes more upward shift in frequency than a corresponding lowering of $\mathrm{M}_{\mathrm{n}}$ can make. The same trend is also reflected when we analyse the values of optimum frequencies for different values of $M_{n}$ and $\mathrm{M}_{\mathrm{p}}$ presented in Table 4. It may be seen from the table that the optimum frequency of oscillation $\left(\mathrm{f}_{\mathrm{P}}\right)$ increases by $5 \%(0.515 \mathrm{THz}$ to $0.540 \mathrm{THz})$ and $12.6 \%(0.515 \mathrm{THz}$ to $0.580 \mathrm{THz})$ as $\mathrm{M}_{\mathrm{n}}$ and $\mathrm{M}_{\mathrm{p}}$ reduce from $10^{6}$ to 10 , respectively.

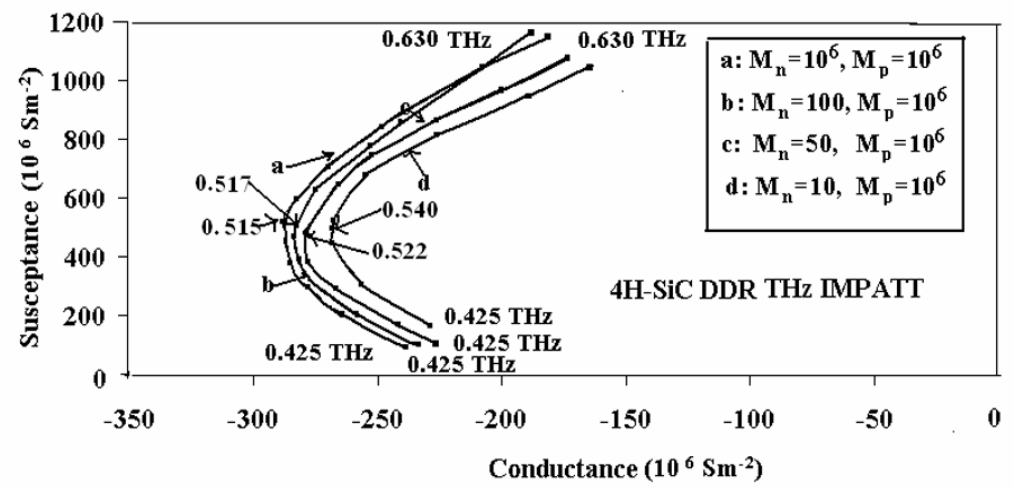

Fig.(5): Conductance versus Susceptance plots of the unilluminated $4 \mathrm{H}-\mathrm{SiC}$ flat profile DDR IMPATT diode (a) and the illuminated diode (b-d) for different values of $M_{n}$. 


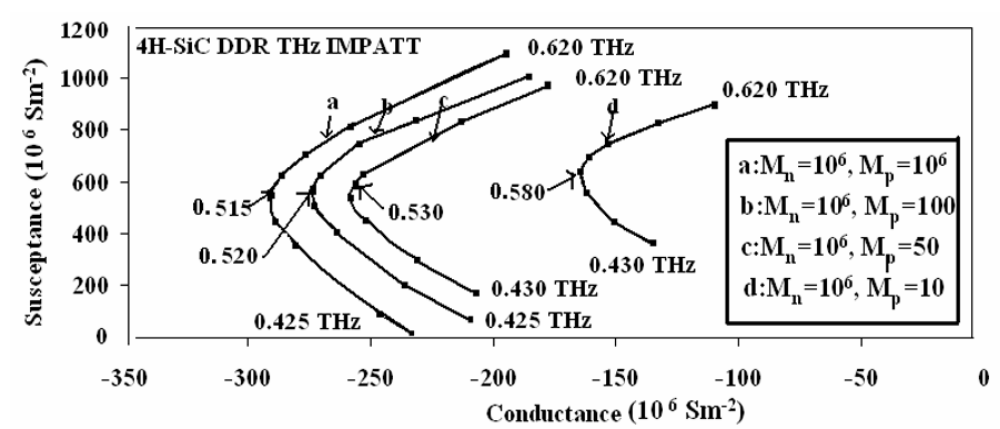

Fig.(6): Conductance versus Susceptance plots of the unilluminated $4 \mathrm{H}-\mathrm{SiC}$ flat profile DDR IMPATT diode (a) and the illuminated diode (b-d) for different values of $M_{p}$.

Figure (7 and 8$)$ show the negative resistivity profiles at the peak frequencies corresponding to different values of $M_{n}\left(M_{p}=10^{6}\right)$ and $M_{p}$ $\left(\mathrm{M}_{\mathrm{n}}=10^{6}\right)$, respectively for $4 \mathrm{H}-\mathrm{SiC}$ DDR IMPATT. In each case, the profiles are characterized by two negative resistivity peaks in the middle of the two drift layers of the diode interspaced by a dip in the avalanche region. It is observed from the figures that due to the enhancement of electron and hole photocurrents, the negative resistivity peaks in the electron and hole drift layers are depressed gradually. It is also found that the decrease in the magnitude of the negative resistivity peaks are more pronounced for variation of $\mathrm{M}_{\mathrm{p}}$ corresponding to hole dominated photocurrent than for the same variation of $\mathrm{M}_{\mathrm{n}}$ corresponding to electron dominated photocurrent.

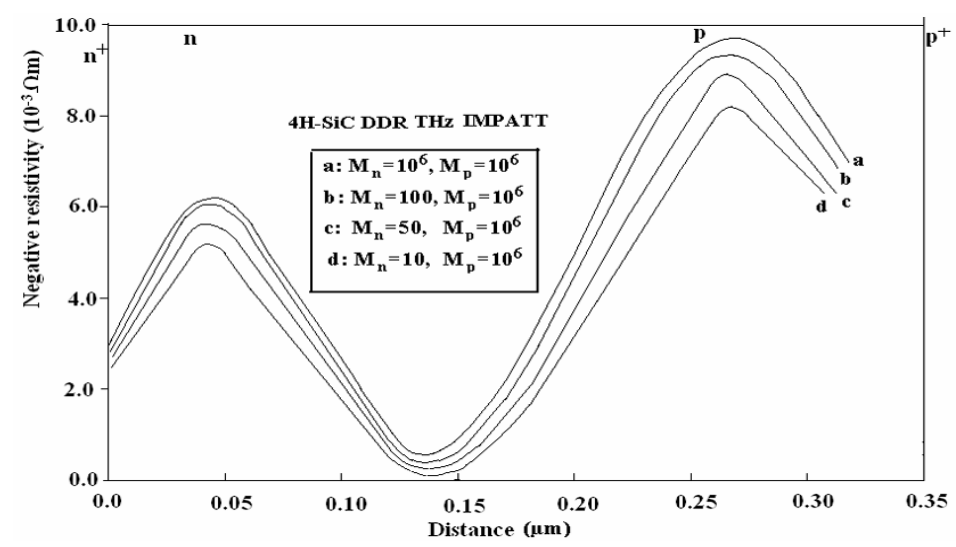

Fig.(7): Variation of negative resistivity profiles of the unilluminated $4 \mathrm{H}-\mathrm{SiC}$ flat profile DDR IMPATT diode (a) and the illuminated diode (b-d) for different values of $\mathrm{M}_{\mathrm{n}}$, and corresponding values of optimum frequencies, $\mathrm{f}_{\mathrm{P}}$ :

a: $M_{n}=10^{6}, M_{P}=10^{6}, f_{P}=0.515 \mathrm{THz}$; 
b: $M_{n}=100, M_{P}=10^{6}, f_{P}=0.517 \mathrm{THz} ; \mathrm{c}: M_{n}=50, M_{P}=10^{6}, f_{P}=0.522 \mathrm{THz} ; \mathrm{d}: M_{n}=10$, $\mathrm{M}_{\mathrm{P}}=10^{6}, \mathrm{f}_{\mathrm{P}}=0.540 \mathrm{THz}$.

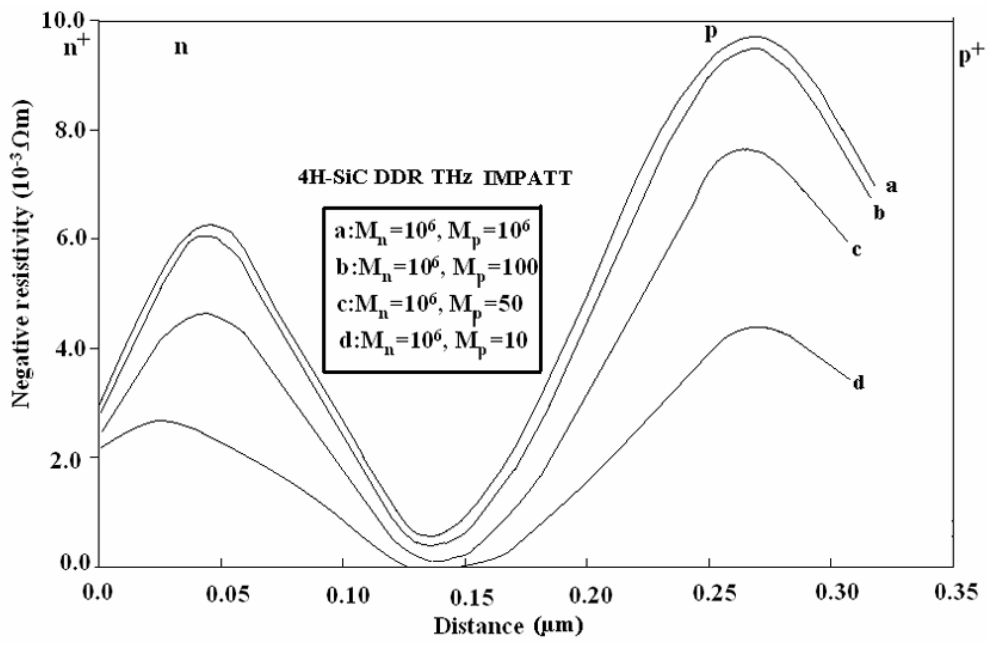

Fig.(8): Variation of negative resistivity profiles of the unilluminated $4 \mathrm{H}-\mathrm{SiC}$ flat profile DDR IMPATT diode (a) and the illuminated diode (b-d) for different values of $\mathrm{M}_{\mathrm{p}}$, and corresponding values of optimum frequencies, $\mathrm{f}_{\mathrm{P}}$ :

a: $\mathrm{M}_{\mathrm{p}}=10^{6}, \mathrm{M}_{\mathrm{n}}=10^{6}, \mathrm{f}_{\mathrm{P}}=0.515 \mathrm{THz}$;

b: $M_{p}=100, M_{n}=10^{6}, f_{P}=0.520 \mathrm{THz} ; \mathrm{c}: M_{p}=50, M_{n}=10^{6}, f_{P}=0.530 \mathrm{THz}$; $\mathrm{d}: \mathrm{M}_{\mathrm{p}}=10, \mathrm{M}_{\mathrm{n}}=10^{6}, \mathrm{f}_{\mathrm{P}}=0.580 \mathrm{THz}$.

Simulation study also depicts that in case of $4 \mathrm{H}-\mathrm{SiC}$ DDR IMPATT, as $M_{n}$ is decreased from $10^{6}$ to 10 , there occurs a $15 \%$ decrease in the diode negative resistance $\left(-Z_{\mathrm{Rp}}\right)$. On the other hand, as $\mathrm{M}_{\mathrm{p}}$ changes from $10^{6}$ to 10 , $-\mathrm{Z}_{\mathrm{Rp}}$ reduces by $61 \%$ (Table (4)).

The variations of power output with optimum frequency for different values of $M_{n}$ and $M_{p}$ are also shown in Table 4. Again, it is found from the study that the magnitude of device quality factor at optimum frequency of oscillation $\left|-\mathrm{Q}_{\mathrm{P}}\right|$ increases appreciably for a decrease of $\mathrm{M}_{\mathrm{p}}$ compared to the same change of $M_{n}$ values (Table (4)).

The enhancement of leakage currents by electron and hole dominated photocurrents thus lead to a decrease of $-Z_{R P},-G_{P}$ and $P_{R F}$ along with a simultaneous upward shift of $f_{P}$. While the photo generated leakage current dominated by holes modulates the dc and high-frequency properties of the device appreciably, that dominated by electrons has relatively less effect in modulating the same. For the mm-wave Si DDR, it was reported that the 
electron saturation current was more dominant in changing the $P_{R F}$ and the $f_{P}$ [19]. In $\mathrm{Si}$, the electron ionization rate is greater than the hole ionization rate. This means that by controlling the DDR IMPATT action through more ionizing carriers in $\mathrm{Si}$, a higher frequency shift may be achieved. By the same logic it can also be concluded that in $4 \mathrm{H}-\mathrm{SiC}$, holes are more ionizing carriers than electrons, since 4H-SiC DDR IMPATT under optical illumination at $\mathrm{THz}$ region is more sensitive to hole dominated photocurrent. This relative predominance of hole leakage current in optical control of $4 \mathrm{H}-\mathrm{SiC}$ DDR IMPATT performance can be attributed to the inequality of the ionization coefficient values in $4 \mathrm{H}-\mathrm{SiC}$ [3].

\section{Conclusions:}

A detailed simulation study of the high frequency behavior of $4 \mathrm{H}-\mathrm{SiC}$ based flat profile DDR IMPATT diode operating at $0.515 \mathrm{THz}$ frequency was reported for the first time. It was found that high RF power (Watt level) might be obtained from $4 \mathrm{H}-\mathrm{SiC}$ IMPATT with appreciable efficiency even at $\mathrm{THz}$ frequency regime. Further, a systematic study was carried out on the effect of optical illumination on $4 \mathrm{H}-\mathrm{SiC}$ IMPATT device at $\mathrm{THz}$ range of frequencies. It was observed that the frequency of oscillation of the device increased gradually under optical illumination. The upward shift of optimum frequency of operation was found to be more $(65 \mathrm{GHz})$ when the performance of the $\mathrm{THz} 4 \mathrm{H}-\mathrm{SiC}$ IMPATT was controlled by hole dominated photocurrent, rather than by electron dominated photo current. However, the peak negative conductance and the $\mathrm{P}_{\mathrm{RF}}$ of the illuminated diodes were found to decrease. It was thus evident from the studies that $4 \mathrm{H}-\mathrm{SiC}$ DDR IMPATT diode exhibited satisfactory dynamic performance even at $\mathrm{THz}$ frequency range, as well as the diode exhibited better response to external radiation. Our findings on the optical control of THz IMPATT may be utilized for realizing optically integrated $\mathrm{THz}$ modules for applications in interstellar explorers.

\section{Acknowledgment:}

The authors wish to express their gratitude to the Director, International Institute of Information Technology, Kolkata for his interest in the work.

\section{References}

1. R. J. Trew, IEEE Trans. Electron Dev. 52, 638 (2005). 
2. L Yuan, M. R. Melloch Jr., J A Cooper and K. J. Webb, IEEE /Cornell Conf. Advanced Concepts in High Speed Semiconductor Devices and Circuit, Ithaca, NY, August 7-9, (2000)

3. J. H. Zhao, V. Gruzinskis, Y. Luo,M. Weiner, M. Pan, P. Shiktorov, E. Starikov, Semicond. Sci. Technol., 15 (11), 1093 (2000).

4. K.V. Vassilevski, A.V. Zorenko, K. Zekentes, K.Tsagaraki, E.Bano, C.Banc and A. A. Lebedev, Materials Science Forum. 389-393, 1353 (2002)

5. H.P. Vyas, R.J. Guttmann and J.M .Borrego, IEEE Trans Electron Devices ED-26, 232 (1979)

6. A. J. Seeds, J. F. Singleton, S. P. Brunt and J. R. Forrest, J Lightwave Technol. LT-5, 403 (1987)

7. N. Mazumder, J. P. Banerjee and S. K. Roy, phys. Stat. solidi. (a) 116, 415 (1989)

8. N. Mazumder and S. K. Roy, Int J Electronics 71, 227 (1991)

9. N. Mazumder and S. K. Roy, phys. Stat. solidi. (a) 137, 267 (1993).

10. S. K Roy, J .P. Banerjee and S. P. Pati, Proc. $4^{\text {th }}$ Conf. on Num. Anal. of Semiconductor Devices. (NASECODE IV) (Dublin: Boole) (Ed. J.H. Miller) 494 (1985)

11. D. L. Scharfetter and H. K. Gummel, IEEE Trans. Electron Devices, 16, 64 (1969)

12. H. K. Gummel and J. L. Blue, IEEE Trans. Electron Devices, ED -14, 569 (1967)

13. H. Eisele and G .I. Haddad, "Microwave Semiconductor Device Physics", Ed. S. M. Sze, Wiley, New York, 1997, p. 343

14. A. Konstantinov, Q. Wahab, N. Nordell, U. Linderfelt, Material. Science Forum, 264-268, 513 (1998)

15. A. Khan and J. A. Cooper, IEEE Trans. Electron Devices 47, 269 (2000)

16. www.cree.com

17. Electronic Archive: New Semiconductor Materials, Characteristics and Properties (online) www.ioffe.ru/SVA/NSM/Semicond/SiC

18. L. Yuan, Ph.D. Thesis, Purdue University, Faculty of Electrical Engineering, Purdue, USA, 2000

19. N. Mazumder and S. K. Roy, Proceedings of the International Conference on Millimeter waves and Microwaves (ICOMM-90), DEAL, Dehradun, India, 19-27 December 1990 (New Delhi, India: Tata McGraw-Hill) 135 